\title{
A comparative prospective study of maternofetal outcome in advanced and younger maternal age group in higher socioeconomic strata
}

\author{
Bilal-ur-Rehman', Rabia Khurshid Sirwal ${ }^{1}$, Feroz Ahmad Wani*
}

\author{
${ }^{1}$ Department of Obstetrics and Gynecology, ${ }^{2}$ Department of Community Medicine, Sher-I-Kashmir Institute of \\ Medical Sciences, Srinagar, Jammu and Kashmir, India
}

Received: 14 January 2017

Accepted: 27 February 2017

\author{
*Correspondence: \\ Dr. Feroz Ahmad Wani, \\ E-mail: drferoz47@gmail.com
}

Copyright: ( ) the author(s), publisher and licensee Medip Academy. This is an open-access article distributed under the terms of the Creative Commons Attribution Non-Commercial License, which permits unrestricted non-commercial use, distribution, and reproduction in any medium, provided the original work is properly cited.

\begin{abstract}
Background: Maternal age in pregnancy is increasing over the world and has been widely documented. Nowadays many women delay their pregnancy even up to the 40th year of life because of different reasons like changing social and economic trend. Simultaneously higher advanced technique and better supported maternal and neonatal care also exist.

Methods: To have an idea of balance between advanced age and advanced support this comparative prospective study was done on 40 advanced and 40 younger maternal age groups to compare the pregnancy outcomes. To find out the association Chi-Square and unpaired ' $t$ ' test was used.

Results: It was observed in this study that Assisted reproductive techniques (mode of conception) and cesarean section rates were significantly higher in advanced maternal age. Although there were no significant differences in antenatal and postpartum complications between the two groups.

Conclusions: It can be concluded that if a women with advanced maternal age is cared at a hospital with advanced techniques, the adverse pregnancy outcomes will not be different from the non-elderly women.
\end{abstract}

Keywords: Advanced maternal age, Assisted reproduction, Lower segment cesarean section, Pregnancy outcome

\section{INTRODUCTION}

According to Williams obstetrics the term advanced maternal age, is defined as age 35 years or more for the mother at the time of delivery of her baby. The definition of advanced maternal age varies from study to study with most of earlier reports fixing the cut off points at 35 years and more recent one around 40 years. ${ }^{1}$ Globally, there is a rising trend among women towards delaying pregnancy and childbirth. This is due to educational status, professional goals, easy access to wide range of modern contraceptive methods and availability of assisted reproductive technology. ${ }^{2}$

Becoming pregnant after the age of 35 years can present a challenge because of the maternal risk factors associated with it, such as-subfertility, miscarriages, pre-eclampsia, gestational diabetes mellitus, anemia, intrauterine growth restriction, antepartum hemorrhage, higher incidence of instrumental deliveries, cesarean section, post-partum hemorrhage and fetal risk factors such as; malpresentation, multiple pregnancy, prematurity, increased NICU admissions due to increased perinatatal morbidity and mortality. ${ }^{3-5}$

To summarize advance maternal age of a pregnant women is a high risk factor and such patients need to be handled by a trained person from the very early stage of pregnancy.

In present study our endeavour was to compare mode of conception, maternal outcome, mode of delivery, perinatal outcome in advanced maternal age and younger maternal age in our set up. 


\section{METHODS}

This hospital based comparative prospective study was conducted from March 2014 to May 2015 among pregnant women who reported to Department of Obstetrics and Gynecology in Saifee Hospital, Mumbai, India after getting clearance from Institutional Ethical Committee and scientific committee.

\section{Sample Size}

Most of the previous studies maternofetal outcome in advanced maternal age, were done in the study setup were patients load was very high and duration of study was long. As our study setup is private tertiary care hospital in an urban area of a metropolitan city, such a high load of patient was not expected considering socioeconomic status of community. Last three years data from the hospital was reviewed and average prevalence of advance maternal age was considered as $10 \%$ for sample size calculation. Using the statistical formula $\mathrm{N}=$ Z2PQ/L2, the sample size came out to be 36 pregnancies of advanced maternal age and 36 pregnancies of younger age group. So it was decided to include 40 participants with advanced maternal age for study (Group A) and for comparison 40 participants with younger maternal age (Group B). In Group A and Group B; participants of age 35 years or above and 20-35 years, respectively with high socioeconomic status according to Kuppuswami scale were included in the study. Deliveries before 20 completed weeks of gestation, women delivering babies with congenital malformation and low and middle socioeconomic status according to Kuppuswami's scale were taken as exclusion criteria's.

From patients admitted in the labour room for delivery after 20 weeks of gestation consecutive 40 patients whose age was $\geq 35$ years were included in study group (Group A) and at the same time patients whose age was <35 years and $>20$ years were included in comparative group (Group B). Written informed consent was obtained from all patients and their attendants. A detailed history was taken \& a complete general, physical examination and investigations was done to confirm the inclusion and exclusion criteria. Participants included in the study were followed till their postpartum period. Data was collected by interviewing subjects, their relatives and reviewing their records. Observations were entered in pre- designed schedule. These observations were inferred with use of chi- square and unpaired t test. The $\mathrm{P}$ value less than 0.05 were taken as statistically significant.

\section{RESULTS}

In the study group (Table 1) maximum number of patients $23(57.5 \%)$ were seen in the age group of 3536years followed by $10(25.0 \%)$ in the age group of $37-$ 38 years. Mean age of women in Group A was 36.8 $( \pm 2.0)$ years. In the comparative group, maximum number of patients $22(55.0 \%)$ were found in the age group of 26-30 years, followed by 9 (22.5\%) and 9 $(22.5 \%)$ in the age group of 21-25 years and 31-34years respectively. Mean age in the Group B was $28.0( \pm 3.0)$ years. In the study Group A number of Primi were 7 (17.5\%), Multi $33(82.5 \%)$ compared to comparative Group B where Primi were 27 (67.5\%), Multi 13 (32.5\%) respectively. The difference in Two Groups was statistically significant $(\mathrm{P}<0.001)$. In study Group A mode of conception was spontaneous in $32(80.0 \%)$, IVFET in $6(15.0 \%)$ and ICSI in $2(5.0 \%)$ as compared to 39 $(97.5 \%), 1(2.5 \%)$ and $0(0 \%)$ in Group B respectively. The difference was statistically significant $(\mathrm{P}=0.044)$.

Table 1: Age, parity and mode of conception of the study population.

\begin{tabular}{|c|c|c|c|c|}
\hline \multicolumn{2}{|c|}{$\begin{array}{l}\text { Age group } \\
\text { (yrs) }\end{array}$} & Frequency & $\%$ & $\begin{array}{l}\text { Mean+SD } \\
\text { (Range) }\end{array}$ \\
\hline \multirow{5}{*}{$\begin{array}{l}\text { Group } \\
\text { A }\end{array}$} & $35-36$ & 23 & 57.5 & \multirow{5}{*}{$\begin{array}{l}36.8 \pm 2.0 \\
(35-44 \mathrm{yrs})\end{array}$} \\
\hline & $37-38$ & 10 & 25.0 & \\
\hline & $39-40$ & 05 & 12.5 & \\
\hline & $>40$ & 02 & 5.0 & \\
\hline & Total & 40 & 100.0 & \\
\hline \multirow{4}{*}{$\begin{array}{l}\text { Group } \\
\text { B }\end{array}$} & $21-25$ & 09 & 22.5 & \multirow{4}{*}{$\begin{array}{l}28.0 \pm 3.0 \\
(21-33 \mathrm{yrs})\end{array}$} \\
\hline & $26-30$ & 22 & 55.0 & \\
\hline & $31-34$ & 09 & 22.5 & \\
\hline & Total & 40 & 100.0 & \\
\hline \multicolumn{5}{|c|}{ Parity of the study population } \\
\hline \multirow{3}{*}{\multicolumn{2}{|c|}{ Primi }} & Group A & Group B & Total \\
\hline & & 07 & 27 & 34 \\
\hline & & $17.5 \%$ & $67.5 \%$ & $42.5 \%$ \\
\hline \multirow{2}{*}{\multicolumn{2}{|c|}{ Multi }} & 33 & 13 & 46 \\
\hline & & $82.5 \%$ & $32.5 \%$ & $57.5 \%$ \\
\hline \multirow{2}{*}{\multicolumn{2}{|c|}{ Total }} & 40 & 40 & 80 \\
\hline & & $100.0 \%$ & $100.0 \%$ & $100.0 \%$ \\
\hline \multicolumn{5}{|c|}{$\chi^{2}=20.460, \mathrm{DF}=1, \mathrm{P}<0.001$ (significant) } \\
\hline \multicolumn{5}{|c|}{ Mode of conception in the study population } \\
\hline \multirow{2}{*}{\multicolumn{2}{|c|}{ Spontaneous }} & 32 & 39 & 71 \\
\hline & & $80.0 \%$ & $97.5 \%$ & $88.8 \%$ \\
\hline \multirow{2}{*}{\multicolumn{2}{|c|}{ IVF-ET }} & 06 & 01 & 07 \\
\hline & & $15.0 \%$ & $2.5 \%$ & $8.8 \%$ \\
\hline \multirow{2}{*}{\multicolumn{2}{|c|}{ ICSI }} & 02 & 00 & 02 \\
\hline & & $5.0 \%$ & $0.0 \%$ & $2.5 \%$ \\
\hline \multirow{2}{*}{\multicolumn{2}{|c|}{ Total }} & 40 & 40 & 80 \\
\hline & & $100.0 \%$ & $100.0 \%$ & $100.0 \%$ \\
\hline \multicolumn{5}{|c|}{$\chi^{2}=6.262, \mathrm{DF}=2, \mathrm{P}=0.044$ (significant) } \\
\hline
\end{tabular}

There was increased incidence of antenatal complications (Table 2) in the study group A as compared to comparative group B. Hypertension disorder of pregnancy was the most common antenatal complication seen in $8(20.0 \%)$ patients in Group A and $3(7.5 \%)$ patients in Group B but the difference was statistically insignificant ( $\mathrm{p}=0.194)$. Gestational diabetes mellitus was seen in $10 \%$ patients in Group A but $0 \%$ in Group B. But the difference in two groups was statistically insignificant $(\mathrm{p}=0.124)$. Antepartum haemorrhage was seen in 3 (7.5\%) of patients in the Group A as compared to $0 \%$ 
patients in Group B but the difference was statistically insignificant $(p=0.239)$. IUGR fetus seen in $2(5.0 \%)$ patient in group $\mathrm{A}$ and $0 \%$ patient in group $\mathrm{B}$ but the difference was statistically insignificant $(\mathrm{P}=0.474)$. Preterm labour was seen in $4(10.0 \%)$ patients in Group A as compared to $3(7.5 \%)$ patients in Group B but the difference was statistically insignificant $(\mathrm{p}=1.000)$.

Table 2: Antenatal complications of the study population.

\begin{tabular}{|lll|l|}
\hline $\begin{array}{l}\text { ANC } \\
\text { complications }\end{array}$ & Group A & Group B & p value \\
\hline PIH & $8(20.0 \%)$ & $3(7.5 \%)$ & 0.194 \\
\hline Gestational DM & $4(10.0 \%)$ & 0 & 0.124 \\
\hline APH & $3(7.5 \%)$ & 0 & 0.239 \\
\hline IUGR & $2(5.0 \%)$ & 0 & 0.474 \\
\hline Preterm & $4(10.0 \%)$ & $3(7.5 \%)$ & 1.000 \\
\hline Breech & $2(5.0 \%)$ & 0 & 0.474 \\
\hline Oligohydramnios & $2(5.0 \%)$ & $1(2.5 \%)$ & 1.000 \\
\hline Polyhydramnios & $2(5.0 \%)$ & 0 & 0.474 \\
\hline $\begin{array}{l}\text { Multiple } \\
\text { pregnancy }\end{array}$ & $2(5.0 \%)$ & 0 & 0.474 \\
\hline
\end{tabular}

Table 3: Intranatal course of the pregnancy.

\begin{tabular}{|c|c|c|c|}
\hline & Group A & Group B & Total \\
\hline \multicolumn{4}{|c|}{ Onset of labour } \\
\hline \multirow{2}{*}{ Spontaneous } & 21 & 25 & 46 \\
\hline & $52.5 \%$ & $62.5 \%$ & $57.5 \%$ \\
\hline \multirow{2}{*}{ Induced } & 10 & 13 & 23 \\
\hline & $25.0 \%$ & $32.5 \%$ & $28.8 \%$ \\
\hline \multirow{2}{*}{ NIL } & 9 & 2 & 11 \\
\hline & $22.5 \%$ & $5.0 \%$ & $13.8 \%$ \\
\hline \multirow{2}{*}{ Total } & 40 & 40 & 80 \\
\hline & $100.0 \%$ & $100.0 \%$ & $100.0 \%$ \\
\hline \multicolumn{4}{|c|}{$\chi^{2}=5.194, \mathrm{DF}=2, \mathrm{P}=0.075$ (Not significant) } \\
\hline \multicolumn{4}{|c|}{ Mode of delivery } \\
\hline \multirow{2}{*}{ Vaginal } & 14 & 27 & 41 \\
\hline & $35.0 \%$ & $67.5 \%$ & $51.2 \%$ \\
\hline \multirow{2}{*}{ Instrumental } & 2 & 2 & 4 \\
\hline & $5.0 \%$ & $5.0 \%$ & $5.0 \%$ \\
\hline \multirow{2}{*}{ LSCS } & 24 & 11 & 35 \\
\hline & $60.0 \%$ & $27.5 \%$ & $43.8 \%$ \\
\hline \multirow{2}{*}{ Total } & 40 & 40 & 80 \\
\hline & $100.0 \%$ & $100.0 \%$ & $100.0 \%$ \\
\hline \multicolumn{4}{|c|}{$\chi^{2}=8.951, \mathrm{DF}=2, \mathrm{P}=0.011$ (Significant) } \\
\hline \multicolumn{4}{|c|}{ Types of LSCS } \\
\hline \multirow{2}{*}{ Elective } & 7 & 3 & 10 \\
\hline & $29.2 \%$ & $27.3 \%$ & $28.6 \%$ \\
\hline \multirow{2}{*}{ Emergency } & 17 & 8 & 25 \\
\hline & $70.8 \%$ & $72.7 \%$ & $71.4 \%$ \\
\hline \multirow{2}{*}{ Total } & 24 & 11 & 35 \\
\hline & $100.0 \%$ & $100.0 \%$ & $100.0 \%$ \\
\hline \multicolumn{4}{|c|}{$\chi^{2}=0.013, \mathrm{DF}=1, \mathrm{P}=0.908$ (Not significant) } \\
\hline
\end{tabular}

Although malpresentation was seen in 2 (5.0\%) of patients in Group A as compared to 0 patients in Group B but the difference was statistically insignificant $(\mathrm{p}=0.474)$. Oligohydramnios was seen in $2(5.0 \%)$ patients in Group A and 1 (2.5\%) Patient in Group B but the difference was statistically insignificant $(\mathrm{p}=1.000)$. Polyhydramnios was seen in $2(5.0 \%)$ patient in Group A, and 0 patients in Group B but the difference in two groups is statistically insignificant. Multiple gestations were seen in $2(5.0 \%)$ patients in Group A as compared to 0 patients in Group B. The difference between two groups was statistically insignificant $(p=0.474)$. All cases of multiple gestations in Group A were twins. In study group A, $10 \%$ of patients delivered preterm as compared to $7.5 \%$ in comparative group B. But the difference in two groups was statistically insignificant $(\mathrm{p}=0.692)$.

Intranatal course of the pregnancy is shown in Table 3. In Study Group A 31 patients who went into labour, labour was spontaneous in onset in $21(52.5 \%)$ patients whereas it was induced in $10(25.0 \%)$. In Comparative Group B38 patients who went into labour, labour was spontaneous in onset in $25(62.5 \%)$ patients while it was induced in 13 $(32.5 \%)$. The difference between these two groups was statistically not significant $(\mathrm{p}=0.075)$. Vaginal deliveries were seen in only $14(35.0 \%)$ patients in study Group A as compared to $27(67.5 \%)$ in comparative Group B. Caesarean section was performed in $24(60.0 \%)$ patients in study Group A as compared to $11(27.5 \%)$ patients in comparative Group B. Instrumental deliveries in study were $2(5.0 \%)$ in each group. The difference in the mode of delivery between two groups was statistically significant $(p<0.030)$. The incidence of emergency caesarean sections was higher in the Group A. In the study Group A 17 (70.8\%) out of 24 caesareans were emergency as compared to $8(72.7 \%)$ out of 11 caesareans in comparative Group B. The differences between two groups were not significant $(\mathrm{p}=0.908)$.

Table 4: Postnatal complications in the study population.

\begin{tabular}{|lll|}
\hline Post-partum complication & Group A & Group B \\
\hline Inadequate lactation & $5(12.5 \%)$ & $3(7.5 \%)$ \\
\hline PPH & $2(5.0 \%)$ & $1(2.5 \%)$ \\
\hline Puerperal sepsis & $1(2.5 \%)$ & 0 \\
\hline Total & $8(20 \%)$ & $4(10 \%)$ \\
\hline$\chi^{2}=1.569, \mathrm{DF}=1, \mathrm{P}=0.210$ (Not significant) \\
\hline
\end{tabular}

There was increase in postpartum complications (Table 4) in study Group A ( $20 \%$ ) as compared to comparative Group B (10\%) and the difference between the two groups was statistically insignificant $(p=0.0 .210)$. Postpartum haemorrhage was the most common complication seen in $2(5.0 \%)$ patients in study Group A as compared to $1(2.5 \%)$ in comparative Group B. Inadequate lactation and puerperal sepsis were seen in 5 $(12.5 \%)$ and $1(2.5 \%)$ patients in study Group A as 
compared to $3(7.5 \%)$, and 0 patients in comparative Group B respectively.

Mean birth weight of babies in study Group A was 3.10 $( \pm 0.65) \mathrm{kg}$ as compared to $3.03( \pm 0.53) \mathrm{kg}$ in comparative Group B. The difference in weight between two groups was statistically insignificant $(p=0.682)$. There was no statistically significant difference between numbers of low birth weight babies in the two groups. The number of low birth weight babies in Group A was 6 (15.0\%) as compared to $4(10.0 \%)$ in Group B. The difference was statistically insignificant $(\mathrm{p}=0.735)$. Although $4(10.0 \%)$ of babies in Group A were macrosomic as compared to 1 $(2.5 \%)$ in Group B but the difference was statistically insignificant $(\mathrm{p}=0.622)$ (Table 5).

Table 5: Comparison of fetal outcome among two groups.

\begin{tabular}{|c|c|c|c|}
\hline Birth Weight & Group A & Group B & P value \\
\hline Mean & 3.10 & 3.03 & \multirow{3}{*}{0.611} \\
\hline SD & 0.65 & 0.53 & \\
\hline $\mathrm{N}$ & 40 & 40 & \\
\hline \multicolumn{4}{|l|}{ Birth Weight } \\
\hline$<2.5 \mathrm{~kg}$ & $6(15.0 \%)$ & $4(10.0 \%)$ & 0.735 \\
\hline$>4 \mathrm{~kg}$ & $4(10.0 \%)$ & $1(2.5 \%)$ & 0.356 \\
\hline \multicolumn{4}{|c|}{ Neonatal Complication } \\
\hline APGAR $<7$ & $8(20.0 \%)$ & $4(10.0 \%)$ & 0.348 \\
\hline NICU & $11(27.5 \%)$ & $4(10.0 \%)$ & 0.086 \\
\hline $\begin{array}{l}\text { Perinatal } \\
\text { mortality }\end{array}$ & $1(2.5 \%)$ & 0 & 1.000 \\
\hline
\end{tabular}

Out of 42 babies delivered in study Group A 8 (20.0\%) had Apgar score $<7$ as compared to $4(10.0 \%)$ out of 40 in comparative Group B. The difference was statistically insignificant $(p=0.348) .11(27.5 \%)$ babies in study Group A were admitted in NICU as compared to 4 $(10.0 \%)$ in comparative Group B and the difference was statistically insignificant $(\mathrm{P}=0.086)$. Of the $11 \mathrm{NICU}$ admissions in the study Group A, 3 were due to prematurity, 5 due to respiratory distress, 1 due to septicemia, 3 due to low birth weight. Of the 4 (10.0\%) admissions in the comparative Group B, 3 were due to prematurity, 1 due to birth asphyxia. There perinatal mortality in study Group A was 1 (2.5\%) as compared to 0 in comparative Group B and this difference was statistically not significant $(\mathrm{p}=1.000)$ (Table 5).

\section{DISCUSSION}

Pregnancy in elderly women $\geq 35$ years of age is considered a high risk pregnancy associated with increased adverse maternal and foetal outcome. Many studies have analyzed this effect. Total 80 cases included in this study, among that 40 women were in study Group A whose age was 35 years and above and 40 patients in comparative group B whose age was more than 20 years but less than 35 years. The study was conducted to study the effect of advanced maternal age on mode of conception, antenatal complications, mode of delivery, post-partum complications, and perinatal outcome. In our study the mean age of women in advanced maternal age was $36.8 \pm 2.0$ years which was comparable to study conducted by Ramachandran $\mathrm{N}$ et al $(2015)^{2}$ where mean age was 37.1 years. The majority of patient were multigravida $82.5 \%$ in advanced maternal age which was comparable to study conducted by Najah AR et al $96.03 \% .^{6}$ The difference in mode of conception was statistically significant $(\mathrm{P}=0.044)$ as assisted conception was more in advanced maternal age. Study by Pawde A, et al. also concluded that rate of assisted conception was significantly higher among women aged 35 years and above. $^{5}$

Our study shows that pregnancy induced hypertension was slightly in higher proportion in advanced maternal age than younger maternal age $(20 \%$ and $7.5 \%$ respectively) but this variation in proportions was not statistically significant as evidenced by other studies as well. ${ }^{7}$ But many authors like Naqvi MM et al, Amarin $\mathrm{VN}$ et al and Ziadeh SM et al reported significantly higher proportion of pregnancy induced hypertension in elderly primigravida than non-elderly. ${ }^{8-10}$ This could be because most of the previous studies were done in study set up were patient load was very high and duration of study was long. In our study the gestational diabetes was $1.43 \%$ in advanced maternal age as compared to $0 \%$ in younger counterpart, but the difference was statistically insignificant and the same was concluded by Kessier L et al. $^{11}$

The antepartum hemorrhage in this study was slightly in higher proportion in advanced maternal age than younger maternal age $(7.5 \%$ and $0 \%$ respectively), but this variation in proportions was also not significant which is consistent with the many other studies. ${ }^{7,12}$ The reason could be the better care provided for antenatal complications in private tertiary care hospital in an urban area of metropolitan city. Our study shows that multiple pregnancy and malpresentation was slightly in higher proportion in advanced maternal age than younger maternal age (2\% and $0 \%$ and $5 \%$ and $0 \%$ respectively), but the difference was statistically insignificant. Many authors like Edge VL et al and Amarin VN et al had statistically significant higher proportion of multiple pregnancies and mal presentation in elderly women than non-elderly women. ${ }^{9,13}$ This could be because most of the previous studies were done in study set up were patient load was very high and duration of study was long.

The incidence of preterm labour was $10.0 \%$ in advanced maternal age as compared to $7.5 \%$ in younger maternal age but the difference was statistically insignificant. The difference was insignificant in Kessier L et al study but statistically significant difference was observed by Ojule JD et al where preterm delivery rate was $10.8 \%$ in elderly and $5.1 \%$ in non-elderly. ${ }^{11,14}$ Normal vaginal delivery was present in significantly lower number of advanced maternal age than younger age $(35.0 \%$ vs. $67 . \%$ 
respectively) as compared to LSCS and assisted instrumental delivery that were done more in advanced maternal age and the difference was statistically significant $(\mathrm{p}=0.030)$. Many author like Naqvi MM et al and Ustun $\mathrm{Y}$ et al also found statistically significant difference in mode of deliveries in elderly and nonelderly women. ${ }^{8,15}$ According to them LSCS was more prevalent mode of delivery in elderly patients as compared to non-elderly patients.

Our study shows that postpartum hemorrhage was slightly in higher proportion in advanced maternal age than younger counterpart ( $20 \%$ vs. $10 \%$ respectively) but this variation in proportion was not found significant. Many author like Edge VL et al, Amarin VN et al, reported a higher incidence of postpartum hemorrhage, $9.6 \%$ in women aged $\geq 35$ years as compared to $5.5 \%$ in women aged 20-25 years. ${ }^{9,13}$

Our study shows that the Mean birth weight of babies was $3.10( \pm 0.65) \mathrm{kg}$ and $3.03( \pm 0.53) \mathrm{kg}$ in the advanced maternal age and younger counterpart respectively and the difference was not statistically significant $(p=0.611)$. Ustun $\mathrm{Y}$, et al, also did not find any significant difference in the birth weight of babies born to mother $<35$ years and those born to mothers $\geq 35$ years of age. ${ }^{15}$

The percentage of low birth weight babies in advanced maternal age was $15 \%$ as compared to $10 \%$ in younger counterpart which was statistically not significant and was consistent with Amarin VN, et al study. ${ }^{9}$ Study by Dulitzki MD et al concluded that the incidence of Apgar score $<7$ at 5 minute was not influenced by maternal age and same was the case with our study. ${ }^{16}$ There was no significant difference in the NICU (neonatal intensive care unit) admissions between advanced maternal age and younger maternal age $(27.5 \%$ vs. $10 \%$ respectively). Ustun Y. et al, also didn't find any significant difference in the incidence of NICU admissions in new born to mothers $\geq 35$ years of age as compared to those born to mothers $<35$ years of age but the incidence was lower ( $7.8 \%$ and $6.7 \%$ respectively). ${ }^{15}$

There was no statistically significant difference in perinatal mortality between the advanced maternal age and younger counterpart $(2.5 \%$ vs. $0 \%$ respectively). Zaideh SM also concluded that despite the increased risk of complications, perinatal mortility of advanced maternal age was similar to that of younger counterpart. ${ }^{10}$

\section{CONCLUSION}

Women with advanced maternal age are at higher risk of complications from conception till delivery and should be provided close supervision for better pregnancy outcome. So it can be concluded that if a women with advanced maternal age is cared at a hospital with advanced techniques these adverse pregnancy outcome may not have significant difference in elderly and non-elderly women or it can be managed.

\section{ACKNOWLEDGEMENTS}

We thank our colleagues and paramedic staff that provided us support and information that was necessary to conduct this research.

\section{Funding: No funding sources}

Conflict of interest: None declared

Ethical approval: The study was approved by the Institutional Ethics Committee

\section{REFERENCES}

1. Salihu HM, Shupert MN, Slay M, Kirby RS, Alexander GR. Childbearing Beyond Maternal age 50 and fetal outcomes in the united states. J Obstet Gynecol. 2003;102:1006-4.

2. Ramachandran N, Sethuraman D, Nachimuthu V, Natarajan T. Obstetric and perinatal outcome of elderly mothers aged 35 years and above: a comparative study. Int $\mathrm{J}$ Res Med Sci. 2015;3(1):214-9.

3. Cleary-Goldman J, Malone FD, Vidaver J, Ball RH, Nyberg DA, Comstock CH, et al. Impact of maternal age on obstetric outcome. Obstet Gynecol. 2005;105(5.1):983-90.

4. Zahan UM, Suchi FA, Shampi SB, Husan GWMZ. Feto-maternal out-come of advanced maternal age-a clinical study in BSMMU.IOSR J Dent Med Sci. (IOSR-JDMS). 2013;9(5):76-80.

5. Pawde AA, Kulkarni MP, Unni J. Pregnancy in women aged 35 years and above: a prospective observational study. J Obstet Gynaecol India. 2015;65(2):93-6.

6. Rehman NA, Vikram A, Palakki N, Kandy NC. Maternal and fetal outcome in advanced maternal age. JEMDS. 2015;4:10504-8.

7. Nagarwal K, Chandrakanta, Gaur K, Manohar RK. Pregnancy outcome compareison in elderly and non elderly primigravida attending at Mahila Chikitsalay, Jaipur (Rajasthan), India. IMJH. 2015;1(1):24-30.

8. Naqvi MM, Naseem A. Obstetrical risks in the older primigravida. J Coll Physicians Surg Pak. 2004;14(5):278-81.

9. Amarin VN and Akasheh HF. Advanced maternal age and pregnancy outcome. EMHJ. 2001;7(4,5):646-51.

10. Ziadeh SM. Maternal and perinatal outcome in nulliparous women aged 35 and older. Gynecol Obstet Invest. 2002;54(1):6-10.

11. Kessler I, Lancet M, Borenstein R, Steinmetz A. The problem of the older primipara. Obstet Gynecol. 1980;56(2):165-9.

12. Nojomi M, Haghighi L, Bijari B, Rezvani L, Tabatabaee SK. Delayed childbearing: pregnancy and maternal outcomes. Iran J Reprod Med Spr. 2010;8(2):80-5.

13. Edge VL and Laros RK. Pregnancy outcome in nulliparous women aged 35 or older. Am J Obstet Gynecol. 1993;168(6):1881-5. 
14. Ojule JD, Ibe VC, Fiebai PO. Pregnancy outcome in elderly primigravidae. Ann AfrR Med. 2011;10(3):204-8.

15. Ustun Y, Engin-Ustun Y, Meydanli M, Atmaca R, Kafkasli A. Maternal and neonatal outcome in pregnancies in 35 and older age group. J Turkish German Gynecol Assoc. 2005;6(1):46-8.

16. Dulitzki M, Soriano D, Schiff E, Chetrit A, Mashiach S, Seidman DS. Effect of very advanced maternal age on pregnancy outcome and rate of cesarean delivery. Obstet Gynecol. 1998;92(6):935-9.

Cite this article as: Rehman BU, Sirwal RK, Wani FA. A comparative prospective study of maternofetal outcome in advanced and younger maternal age group in higher socioeconomic strata. Int $\mathbf{J}$ Reprod Contracept Obstet Gynecol 2017;6:1362-7. 